\title{
Book Review · Buchbesprechung · Livre nouveau
}

W. Käufmann and D.K. Krause (eds.): Central Nervous Control of NA $\mathbf{A}^{\mp}$ Balance — Relations to the Renin-Angiotensin System. Thiemel, Stuttgart 1976. XIV + 202 ppl, 107 fig.; DM 58.-. ISBN 3-13-5336-01-8.

The book is divided into 5 parts: Part 1 deals with basic physiological and anatomical information concerning functional morphology of the hypothalamus, sodium transport in the fluid compartments of the brain, intrinsic iso-zeninangiotensin system in the brain and Chemical kidney renin-angiotensins system. Part 2 explores interrelationships between angiotensin II and antidiuretic hormone. Part 3 discusses relations between renin angiotensin system and thirst mechanisms. Part 4 is devoted to the escape phenomenon and describes experiences suggesting the existence of a natriuretic factor. Lastly, part 5 deals with central nervous system receptors to Na and their role in the regulation of renal sodium handling. This symposium presents interesting information concerning the new trends in the study of haemostasis of salt and water balance and the possible roles of the renin-angiotensin system.

J. Mendlewicz, Brussels 